\title{
The effect of metabolic acidosis and alkalosis on the blood flow through the cerebral cortex
}

\author{
A. MURRAY HARPER AND RUTH A. BELL \\ From the St. Mungo Department of Surgery and the Wellcome \\ Research Laboratories, University of Glasgow
}

There is conflicting evidence on the effect of 'acids' and 'alkalis' on the cerebral blood vessels. Although Schieve and Wilson (1953) and Lambertsen, Semple, Smyth, and Gelfand (1961) have clearly dissociated the cerebral vasodilatation which occurs on raising the arterial $\mathrm{pCO}_{2}$ from the concomitant fall in blood $p \mathrm{H}$, some workers have claimed that acids dilate and alkalis constrict the cerebral blood vessels (Wolff and Lennox, 1930; Geiger and Magnes, 1947; Kety, Polis, Nadler, and Schmidt, 1948), while opposite effects have been reported by Schieve and Wilson (1953) and by Bronk and Gesell (1927).

The recent development by Lassen and Ingvar (1961) of a rapid and easily repeatable method of estimating the blood flow through the brain cortex has enabled us to follow changes in blood flow through a wide range of $p \mathrm{H}$ values in the anaesthetized dog, while maintaining a steady arterial carbon dioxide tension by the use of controlled passive ventilation.

\section{METHOD}

The experiments were performed on 10 unselected mongrel dogs. The blood flow through the brain cortex was measured by the method of Lassen and Ingvar (1961), using the injection technique described by Harper, Glass, and Glover (1961). The animals were anaesthetized with thiopentone and suxamethonium chloride. An endotracheal tube was connected to a Palmer respiratory pump, through which a 4:1 mixture of $\mathrm{N}_{2} \mathrm{O}$ and $\mathrm{O}_{2}$ was delivered in open circuit. Repeated small doses of thiopentone were given during the actual operation. A cannula inserted into the femoral artery was connected to a mercury manometer for the measurement of arterial blood pressure and for the withdrawal of arterial blood samples. The thyroid branch of the common carotid artery was cannulated centripetally, the distal end being tied. A trephine hole was made over the parietal bone and a piece of dura $1 \mathrm{~cm}$. in diameter excised. The exposed brain cortex was covered with a thin plastic membrane (Melinex). An end window Geiger counter, mounted $1 \mathrm{~mm}$. above the brain cortex, was connected to a ratemeter and a direct writing recorder.
Dextran, saturated with Krypton 85, was slowly injected into the carotid artery via the cannula in the thyroid artery. The blood flow through the brain cortex was calculated from the clearance rate of the Krypton following its injection. After each measurement of blood flow, blood samples were taken from the femoral artery for the measurement of $\mathrm{pCO}_{2}$ and $p \mathrm{H}$ on an Astrup apparatus (Astrup, 1956).

At the start of each experiment the output from the respiratory pump was adjusted to produce an arterial $\mathrm{pCO}_{2}$ of between 30 and $40 \mathrm{~mm}$. Hg. In five dogs acidosis was induced by the infusion of a $2 \%$ solution of lactic acid in normal saline. In another five dogs alkalosis was induced by the infusion of sodium bicarbonate in saline (50 mEq. in $100 \mathrm{ml}$.). The arterial carbon dioxide tension was held constant by altering the respiratory pump output when necessary.

\section{RESULTS}

The results of the experiments are shown in Tables I and II. The arterial $\mathrm{pCO}_{2}$ was kept relatively constant in each experiment. The maximal deviation (in dog 38) was $\pm 3.5 \mathrm{~mm}$. $\mathrm{Hg}$ from the mean. In the alkalosis experiments the respiratory pump output had to be increased as alkalosis progressed to maintain a constant arterial $\mathrm{pCO}_{2}$. There were slight deviations in mean arterial blood pressure in individual experiments but the deviations were inconstant and were not considered significant.

In the experiments the lowest $p \mathrm{H}$ recorded was 6.74 and the highest $7 \cdot 80$. Even at these extreme levels there was no noticeable alteration in blood flow. In none of the experiments was the correlation coefficient for blood flow against $p \mathrm{H}$ significant.

In Fig. 1, the blood flow estimations from all the experiments have been plotted against the blood $p \mathrm{H}$. The calculated linear regression line was found to be horizontal.

\section{DISCUSSION}

Although various workers have reported vasodilatation occurring with acidosis and constriction with alkalosis, these changes have not been marked. In 
TABLE I

RESULTS OF EXPERIMENTS

Acidosis

\begin{tabular}{|c|c|c|c|c|c|}
\hline $\begin{array}{l}\text { Experi- } \\
\text { ment } \\
\text { No. }\end{array}$ & $p \mathrm{H}$ & $\begin{array}{l}\mathrm{pCO} \mathrm{O}_{2} \\
(\mathrm{~mm} . \mathrm{Hg})\end{array}$ & $\begin{array}{l}\text { Mean } \\
\text { Arterial } \\
\text { Blood } \\
\text { Pressure } \\
(\mathrm{mm} . \mathrm{Hg})\end{array}$ & $\begin{array}{l}\text { Respira- } \\
\text { tion } \\
\text { Pump } \\
\text { Output } \\
\text { (l.|min.) }\end{array}$ & $\begin{array}{l}\text { Flow } \\
(\mathrm{ml} . / \mathrm{g} . / \mathrm{min} .)\end{array}$ \\
\hline
\end{tabular}

28

$\begin{array}{ll}7 \cdot 36 & 34 \\ 7 \cdot 30 & 35 \\ 7 \cdot 19 & 38 \\ 7 \cdot 14 & 39 \\ 7 \cdot 13 & 36 \\ 6 \cdot 97 & 35\end{array}$

34

$7 \cdot 34$

$\begin{array}{ll}7 \cdot 34 & 37\end{array}$

$7 \cdot 30$

$7 \cdot 28$
$7 \cdot 27$

$7 \cdot 20$

$7 \cdot 11$

7.05

6.81

36

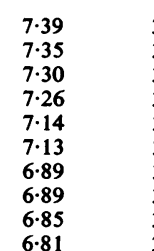

$37 \quad 7.32$

$7 \cdot 32$
$7 \cdot 28$

$7 \cdot 26$

$7 \cdot 19$

$7 \cdot 19$

$7 \cdot 12$

6.96

6.74

38

$\begin{array}{lll}7 \cdot 26 & 37 & 145 \\ 7 \cdot 25 & 38 & 145 \\ 7 \cdot 22 & 37 & 160 \\ 7 \cdot 16 & 36 & 160 \\ 6.98 & 42 & 160 \\ 6 \cdot 85 & 35 & 170 \\ 6.82 & 42 & 160\end{array}$

$6 \cdot 82$

$\begin{array}{lll}145 & 4.55 & 0.84 \\ 155 & 4.55 & 0.88 \\ 155 & 4.55 & 0.89 \\ 155 & 4.81 & 0.83 \\ 145 & 4.81 & 0.90\end{array}$

$\begin{array}{ll}145 & 4.81 \\ 135 & 5.46\end{array}$

$140 \quad 5 \cdot 85$

$145 \quad 5.85$

$140 \quad 5.85$

$145 \quad 6.11$

$145 \quad 5.85$

$\begin{array}{ll}150 & 6 \cdot 37 \\ 155 & 6 \cdot 11\end{array}$

$\begin{array}{ll}155 & 6 \cdot 11 \\ 165 & 6 \cdot 37\end{array}$

$165 \quad 6.37$

$165 \quad 6.37$

$170 \quad 6.50$

$\begin{array}{ll}175 & 6.50 \\ 190 & 6.89\end{array}$

$\begin{array}{ll}190 & 6.89 \\ 195 & 6.76\end{array}$

$\begin{array}{ll}195 & 6 \cdot 76 \\ 175 & 6 \cdot 76\end{array}$

175
185

180

180
180

180
180

185

200

200
210

210

230

210
210

145
145
160
160
160
170
160

6.76

$6 \cdot 76$

$7 \cdot 41$
$6 \cdot 76$

$6 \cdot 76$

$4 \cdot 55$

$4 \cdot 81$

4.55

$4 \cdot 81$

$4 \cdot 81$

5.09

5.07
5.07

$4 \cdot 16$

$4 \cdot 03$
$4 \cdot 16$

$4 \cdot 16$

$4 \cdot 16$

3.90

$4 \cdot 29$
$3 \cdot 90$

0.90

0.62

0.69

0.99

0.64

0.86

0.72
0.72

0.65

0.65
0.73

0.88

0.81

0.86

0.81

0.08

0.84
0.95
Alkalosis

\begin{tabular}{|c|c|c|c|c|c|}
\hline $\begin{array}{l}\text { Experi- } \\
\text { ment } \\
\text { No. }\end{array}$ & $p \mathbf{H}$ & $\begin{array}{l}\text { pCO } \\
(\mathrm{mm} . \mathrm{Hg})\end{array}$ & $\begin{array}{l}\text { Mean } \\
\text { Arterial } \\
\text { Blood } \\
\text { Pressure } \\
\text { (mm. Hg) }\end{array}$ & $\begin{array}{l}\text { Respira- } \\
\text { tion } \\
\text { Pump } \\
\text { Output } \\
\text { (l./min.) }\end{array}$ & $\begin{array}{l}\text { Flow } \\
(\mathrm{ml} . / \mathrm{g} . / \mathrm{min} .)\end{array}$ \\
\hline
\end{tabular}

$\begin{array}{llllll}32 & 7 \cdot 29 & 36 & 195 & 7 \cdot 15 & 0.95 \\ & 7 \cdot 33 & 36 & 200 & 6 \cdot 76 & 0.98 \\ 7 \cdot 34 & 39 & 190 & 6.76 & 0.83 \\ 7 \cdot 39 & 40 & 190 & 7 \cdot 28 & 0.88 \\ 7 \cdot 44 & 39 & 185 & 7 \cdot 80 & 0.75 \\ 7 \cdot 47 & 38 & 185 & 7 \cdot 80 & 0.81 \\ 7 \cdot 49 & 39 & 160 & 6.76 & 0.82 \\ 7 \cdot 51 & 36 & 190 & 7.80 & 0.74 \\ 7 \cdot 58 & 39 & 175 & 7.80 & 0.83 \\ 7 \cdot 59 & 41 & 170 & 8.06 & 0.86\end{array}$

$40 \quad 7 \cdot 28$

$7 \cdot 39$
$7 \cdot 45$

$7 \cdot 45$
$7 \cdot 47$

7.69

45

$7 \cdot 23$
$7 \cdot 25$

$7 \cdot 25$
$7 \cdot 33$

$7 \cdot 38$

$7 \cdot 45$

$7 \cdot 51$

$7 \cdot 53$

$7 \cdot 58$

$7 \cdot 65$
46

$7 \cdot 28$

$7 \cdot 28$
$7 \cdot 40$

$7 \cdot 45$

$7 \cdot 54$

$7 \cdot 55$

$7 \cdot 59$

48

$7 \cdot 32$
$7 \cdot 40$
$7 \cdot 46$
$7 \cdot 58$
$7 \cdot 76$
$7 \cdot 80$

$7 \cdot 80$
38
40
39
42
42

$145 \quad 3.25$

$145 \quad 3 \cdot 25$

$140 \quad 3.51$

130

130

130

135

140
135

135

130

130

130

120

115

140

145
165

165
170

155

175

155

150

160

160

160

155

155

$4 \cdot 29$

3.90
$4 \cdot 16$

4.16

$4 \cdot 29$

4.55

4.68

$5 \cdot 20$

$5 \cdot 46$

5.98

6.63

$7 \cdot 02$

6.89

$7 \cdot 41$

8.06

8.45

$8 \cdot 84$

$8 \cdot 32$

$\mathbf{9 \cdot 2 3}$

$8 \cdot 32$

$8 \cdot 56$

8.97

$9 \cdot 62$

$11 \cdot 70$
$140 \quad 3.51$

0.86

0.87

0.68

0.58

1.04

0.60

0.61

0.54

0.47

0.56

0.58

0.52

0.50

0.51

0.52

1.00

0.79

0.96

0.98

0.76

0.80
0.72

$1 \cdot 14$

$1 \cdot 14$
$0 \cdot 86$

0.82

0.85

0.89

TABLE II

RESULTS OF EXPERIMENTS

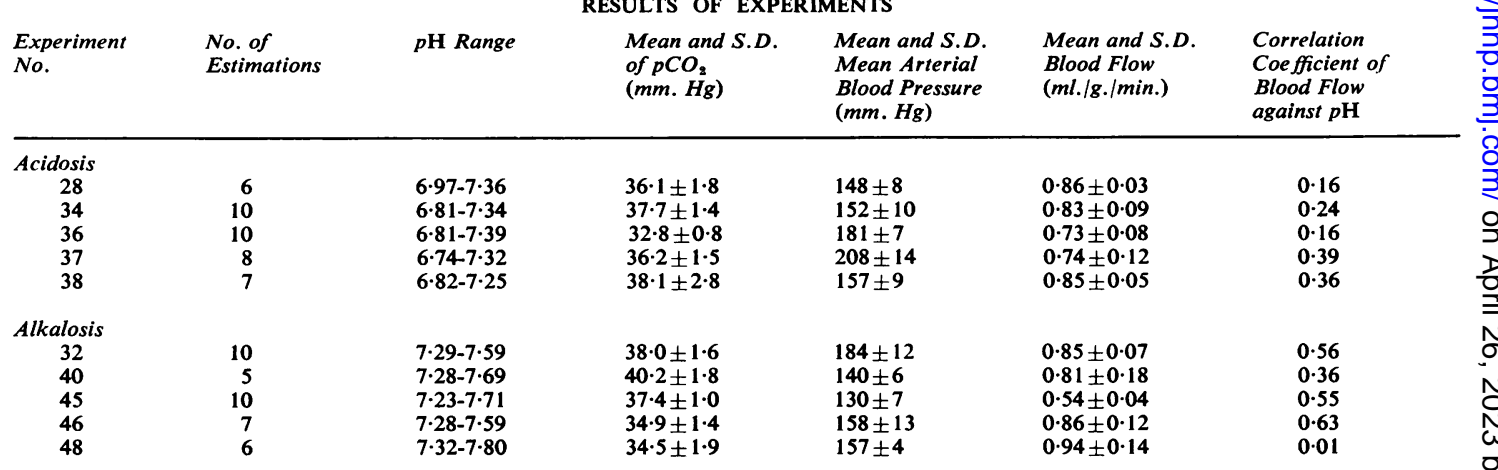




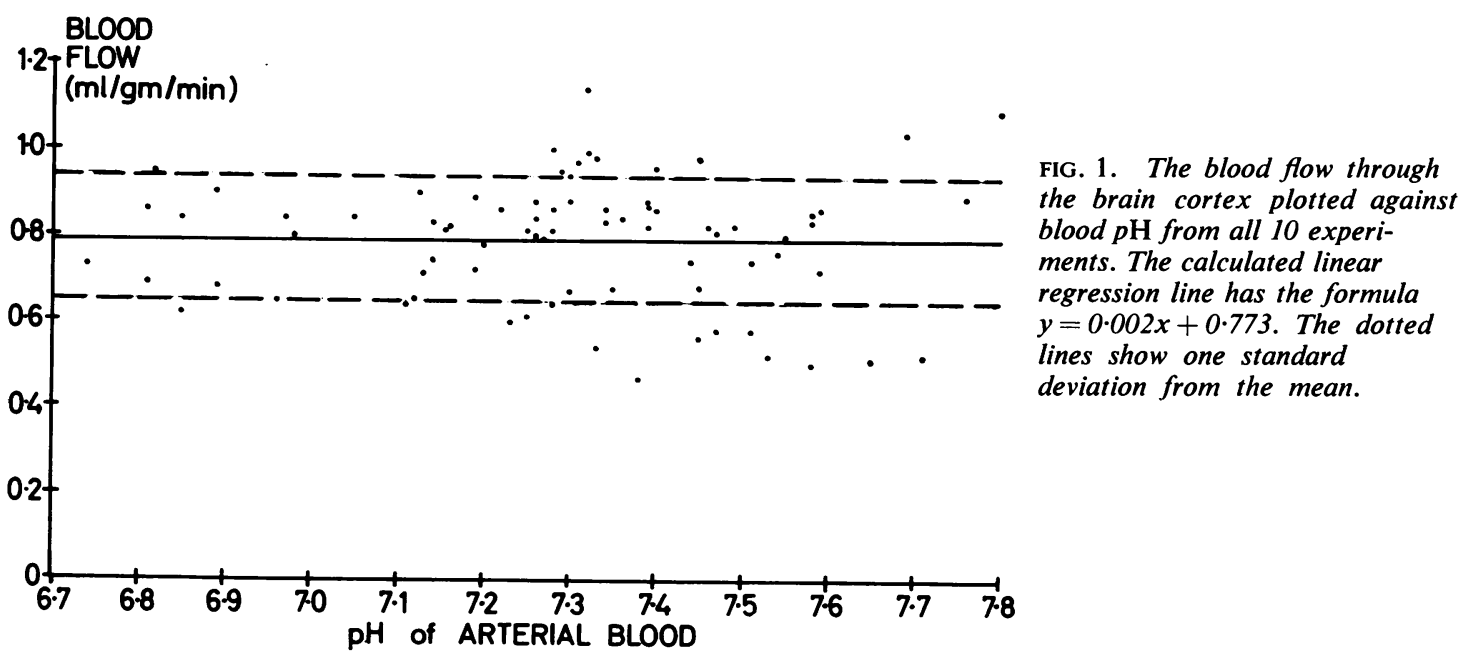

the perfused dog brain Schmidt (1928) reported dilatation by acid and constriction by alkali. In the perfused cat brain Geiger and Magnes (1947) reported that only extreme changes in $p \mathrm{H}$ produced any effect. Using a cranial window technique Wolff and Lennox (1930) reported transient dilatation of the pial arteries in the cat following the injection of lactic acid. However, Schmidt and Pierson (1934) found that the changes produced by acidosis on the blood flow through the medulla were uncertain, and Bronk and Gesell (1927) reported that alkalosis increased the blood flow through the carotid artery.

Kety and his colleagues (1948) found a convincing increase in cerebral blood flow in patients with a metabolic acidosis due to diabetic coma, even although the arterial $\mathrm{pCO}_{2}$ was low. Schieve and Wilson (1953) have questioned whether this increase in cerebral blood flow is due to some factor other than acidosis. They infused ammonium chloride into patients producing a slight acidosis and found a decrease in blood flow. They also found an increase in cerebral blood flow on producing a metabolic alkalosis by infusion of sodium bicarbonate. In the latter studies, however, no figures were given for $\mathrm{pCO}_{2}$.

In these experiments we have tried to achieve as constant experimental conditions as possible in order to ensure that the main variable was the blood $p \mathrm{H}$. The arterial carbon dioxide tension, oxygen saturation, and blood pressure were successfully kept within narrow limits. There is no evidence that there were any variations in the depth of anaesthesia which could have influenced the results: the same concentrations of anaesthetic gas were given throughout each experiment. Under these 'steady state' conditions we did not find any marked alteration in the cortical blood flow in either metabolic acidosis or alkalosis.

However, we have found previously that repeated estimations in any one animal under constant conditions of arterial $\mathrm{pCO}_{2}, p \mathrm{H}$, and blood pressure show a coefficient of variation of $9 \%$ (Harper et al., 1961). It is possible therefore that changes in blood flow of this order might not be revealed in our results. However, changes in blood flow of more than $9 \%$ would almost certainly be noticed as we have shown that the method records faithfully the marked changes which occur in the blood flow on raising and lowering the arterial carbon dioxide tension under the same experimental conditions as in this study (Harper et al., 1961).

Sokoloff (1959) has stated that 'a final evaluation of the direct action of acids and alkalis on the cerebral circulation is difficult because of the usual association of secondary extraneous influences, particularly changes in blood $\mathrm{pCO}_{2}$ '. We believe our study to be the first in which the arterial $\mathrm{pCO}_{2}$ was carefully controlled and only the $p \mathrm{H}$ allowed to vary. Under these circumstances we found that neither acidosis nor alkalosis produced significant changes in the blood flow through the cerebral cortex in anaesthetized dogs.

\section{SUMMARY}

Measurements of the blood flow through the cerebral cortex were made on anaesthetized dogs, using the method of Lassen and Ingvar (1961). In five dogs a metabolic acidosis was induced by the infusion of lactic acid, and in five dogs a metabolic alkalosis was induced by the infusion of sodium bicarbonate, 
the arterial carbon dioxide tension being held constant. Neither metabolic acidosis nor alkalosis produced any significant change in the blood flow through the cerebral cortex.

This work was carried out under the direction of Professor W. A. Mackey and was supported by a grant from the Medical Research Council. We are grateful to Professor W. A. Mackey and Dr. N. A. Lassen for their advice in preparing this paper. Our thanks are due to Mr. H. I. Glass, Regional Physics Department, Western Regional Hospital Board, for his invaluable assistance and advice. Technical assistance was rendered by Mr. F. McLaughlin, Miss M. Anderson, and Miss B. Shuttleton.

\section{REFERENCES}

Astrup, P. (1956). Scand. J. clin. Lab. Invest., 8, 33.

Bronk, D. W., and Gesell, R. (1927). Amer. J. Physiol., 82, 170.

Geiger, A., and Magnes, J. (1947). Ibid., 149, 517.

Harper, A. M., Glass, H. I., and Glover, M. M. (1961). Scot. med. J., 6, 12.

Kety, S. S., Polis, B. D., Nadler, C. S., and Schmidt, C. F. (1948). J. clin. Invest., 27, 500.

Lambertsen, C. J., Semple, S. J. G., Smyth, M. G., and Gelfand, R. (1961). J. appl. Physiol., 16, 473.

Lassen, N. A., and Ingvar, D. H. (1961). Experientia (Basel), 17, 42.

Schieve, J. F., and Wilson, W. P. (1953). J. clin. Invest., 32, 33.

Schmidt, C. F. (1928). Amer. J. Physiol., 84, 202.

, and Pierson, J. C. (1934). Ibid., 108, 241.

Sokoloff, L. (1959). Pharmacol. Rev., 11, 1.

Wolff, H. G., and Lennox, W. G. (1930). Arch. Neurol. Psychia. (Chic.), 23, 1097. 